\title{
THE NEW KEYNESIAN DSGE MODEL AND ALTERNATIVE MONETARY POLICY RULES IN THE CZECH REPUBLIC
}

\author{
Milan Bouda*
}

\section{Introduction}

This paper deals with the impact of alternative monetary policy rules on the economy of Czech Republic. The monetary policy shock is formulated as a part of a New Keynesian model (NKM) where monetary policy is managed using the standard Taylor rule. The main goal of this paper is to verify the suitability of several modifications to the Taylor rule. The NKM maximises the utility function of households, profit of firms and welfare by a central bank. This model is taken from Gali (2008) and applied to the Czech economy. This NKM contains a couple of departures from classical monetary theory. Firstly, imperfect competition on the goods market is introduced by assuming that each firm produces differentiated goods for which it sets the price, instead of taking the price as given. Secondly, some constraints are imposed on the price adjustment mechanism by assuming that only a fraction of firms can reset their prices in any given period. In particular, and following much of the literature, a model of staggered price setting according to Calvo (1983) and characterised by random price durations is adopted. The resulting inflation dynamics can also be derived under the assumption of quadratic costs of price adjustment. For details, see Rotemberg (1982).

The paper is structured as follows. The first chapter describes the general equilibrium equations of the benchmark NKM. Derivation of these equations is not necessary as it may be found in the papers referenced. The second chapter deals with the observed data and calibration of structural parameters of the NKM. The chapter contains a description of both the GDP and inflation time series that are used in the estimation. A list of all the parameters with their economic interpretation and calibrated values is included. This paper is not focused on calibration. Hence, the prior values of the structural parameters are taken from relevant studies and sources. The third chapter contains a short description of methods and algorithms used for the estimation of the NKM. The fourth chapter covers the results of the estimation as parameter estimates, impulse responses, shock decompositions and predictions. The fifth chapter deals with the Taylor rule and its modifications. The sixth chapter contains important results for all the modified NKMs. The seventh chapter contains theory about comparison of

* University of Economics Prague, Faculty of Informatics and Statistics; Česká spořitelna, a.s. (bouda.mil@seznam.cz).

This paper is supported by funding of IGA VŠE, project IG403052. I would also like to thank the anonymous reviewers for their useful points and comments. 
DSGE models. Four NKMs (benchmark and three modifications) are specified and each contains a different monetary policy rule. These models are compared using the Bayesian techniques. This experiment evaluates whether increasingly sophisticated monetary policy rules bring material improvement to the DSGE model.

\section{Benchmark model}

The NKM consists of economic agents of three types. The households purchase goods for consumption, hold money and bonds, supply labour, and maximise the expected present value of utility. The firms hire labour, produce and sell differentiated products on monopolistically competitive goods markets, and maximise profits. The central bank controls the nominal rate of interest. Figure 1 shows the basic structure of the NKM.

\section{Figure 1}

The structure of the New Keynesian model

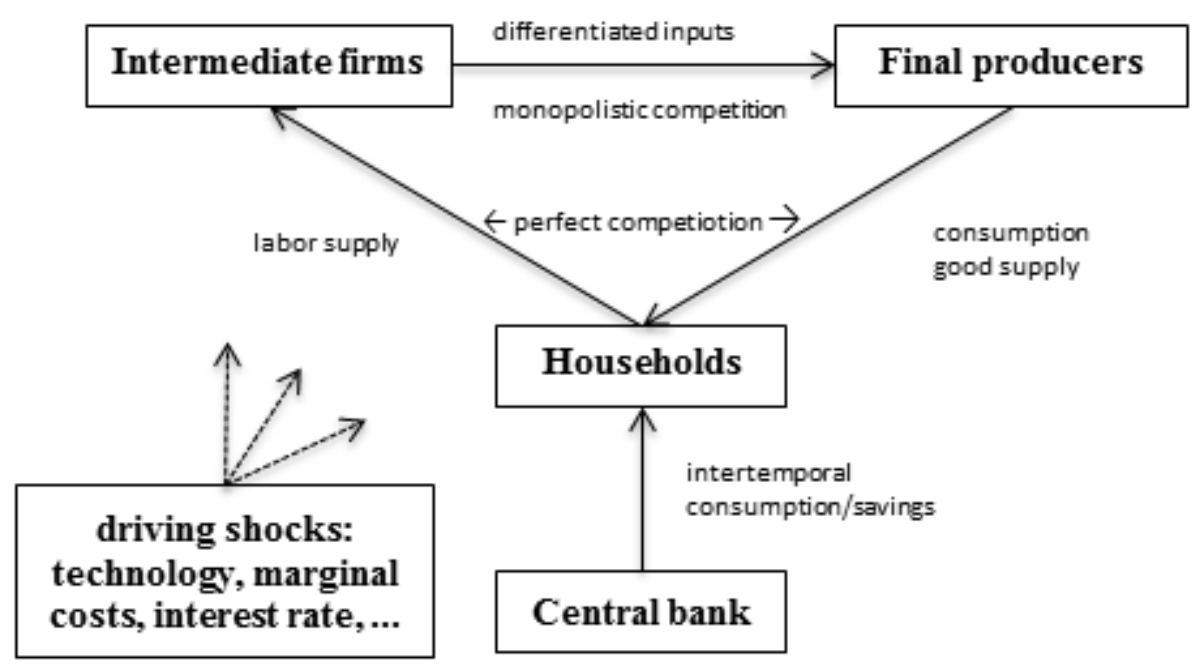

The NKM consists of six general equilibrium equations and two stochastic shock definitions. All equations are log-linearised and variables denoted by a wave are gap variables. Let us start with the dynamic IS equation

$$
\tilde{y}_{t}=-\frac{1}{\sigma}\left(i_{t}-E_{t}\left\{\pi_{t+1}\right\}-r_{t}^{n}\right)+E_{t}\left\{\tilde{y}_{t+1}\right\}
$$

where $\tilde{y}_{t}$ is the output gap, $i_{t}$ is the short-term nominal rate, $E_{t}\left\{\pi_{t+1}\right\}$ is the expected inflation in the next period, $r_{t}^{n}$ is the natural rate of interest, $E_{t}\left\{\tilde{y}_{t+1}\right\}$ represents the expected output gap in the next period, and finally, the parameter $\sigma$ is the coefficient of risk aversion.

The second equation is called the New Keynesian Phillips curve (NKPC)

$$
\pi_{t}=\beta E_{t}\left\{\pi_{t+1}\right\}+\kappa \tilde{y}_{t}
$$


where $\pi_{t}$ is the inflation, $\beta$ is the household discount factor, $\kappa \equiv \lambda\left(\sigma+\frac{\phi+\alpha}{1-\alpha}\right)$ and it is the output gap elasticity of inflation, $\sigma$ is the coefficient of risk aversion, $\phi$ is the elasticity of labour supply, $\alpha$ is the share of capital in the Cobb-Douglas production function and $\lambda=\frac{\theta^{-1}(1-\theta)(1-\beta \theta)(1-\alpha)}{(1-\alpha+\alpha \varepsilon)}$.

The third equation shows the evolution of the natural rate of interest

$$
r_{t}^{n}=\rho+\sigma \psi_{y a}^{n} E_{t}\left\{\Delta a_{t+1}\right\}
$$

where $r_{t}^{n}$ is the natural rate of interest, $\rho$ is the real interest rate in the steady state, $\psi_{y a}^{n}=\frac{1+\phi}{\sigma(1-\alpha)+\phi+\alpha}$ and $E_{t}\left\{\Delta a_{t+1}\right\}$ is the expected change of technological progress in the next period.

The fourth equation is the interest rate rule of the central bank, usually called the Taylor rule. For details, see Taylor (1993).

$$
i_{t}=\rho+\phi_{\pi} \pi_{t}+\phi_{y} \tilde{y}_{t}+v_{t}
$$

where $i_{t}$ is the nominal interest rate, $\phi_{\pi}$ and $\phi_{y}$ is the sensitivity of the central bank with respect to inflation and output gap (both are chosen by the central bank), $v_{t}$ is an exogenous stochastic component with a zero mean. labour

The fifth equation represents the production function consisting of technology and

$$
y_{t}=a_{t}+(1-\alpha) n_{t}
$$

where $y_{t}$ is the output, $a_{t}$ is the level of technology and $n_{t}$ is the number of hours worked.

The sixth equation is the ad-hoc money demand

$$
m_{t}=\pi_{t}+\tilde{y}_{t}-\eta i_{t}
$$

where $m_{t}$ is the money demand and $\eta$ is the elasticity of the money demand with respect to the nominal interest rate.

The last two equations represent stochastic shocks. The technology shock follows an $\operatorname{AR}(1)$ process

$$
a_{t}=\rho_{\alpha} a_{t-1}+\varepsilon_{t}^{a}
$$

with the persistence of the technology shock $\rho_{\alpha} \in\langle 0 ; 1\rangle$ and where $\varepsilon_{t}^{a}$ is a zero-mean white noise process.

Finally, the policy shock follows an AR(1) process

$$
v_{t}=\rho_{\nu} v_{t-1}+\varepsilon_{t}^{v}
$$


with the persistence of the monetary policy shock $\rho_{v} \in\langle 0 ; 1\rangle$. Positive (negative) realisation of $\varepsilon_{t}^{v}$ is interpreted as a contractionary (expansionary) monetary policy shock, leading to a rise (decline) in the nominal interest rate, given inflation, and the output gap. The Czech Republic is a small open economy rather than a closed economy. Thus, there is a need to broaden the interpretation of the monetary policy shock $v_{t}$ to exogenous shock as it would be very unreasonable to associate all $v_{t}$ realisations with monetary policy shocks. The exogenous shock represents monetary policy shock, fiscal policy shock, shocks to domestic and foreign demand, shock to risk premium, housing shock and many others. If one wanted to distinguish the effects of particular shocks, it would be necessary to specify a more complex DSGE model. Such specification is not necessary for the purpose of this paper and it would make this model less transparent for the reader.

\section{Data and calibration}

The NKM for the Czech Republic contains two observed variables. The first one is the Gross Domestic Product (GDP) and the second is the Consumer Price Index (CPI). Both the time series are taken from the database of the Czech National Bank called ARAD. First, I have to transform both the variables into the appropriate form. The GDP is in the constant prices of the year 2005. Next, the GDP is transformed into the year-on-year percentage changes. The GDP is inserted into the model in this final form. The second observed variable, the CPI, is transformed into the inflation, obtained as a moving year average. It is necessary to evaluate whether all the observed variables of a general equilibrium model are stationary, as their stationarity is a very appropriate attribute of the time series. An NKM filled with stationary data is easier to calibrate and then to estimate.

The stationarity may be verified simply by looking at the data or with exact statistical tests, see Green (2012) or Arlt and Arltová (2009). The method used in this paper is the KPSS test; for details, see Kwiatkowski et al. (1992). The null hypothesis says that the time series is stationary. This hypothesis is not rejected (the significance level is $5 \%$ ) for both the time series. Finally, I have 51 observations and the time series are from Q1 2000 to Q3 2012.

\section{Figure 2}

\section{The chart on the left shows the YoY percentage changes in GDP, the chart} on the right presents the inflation

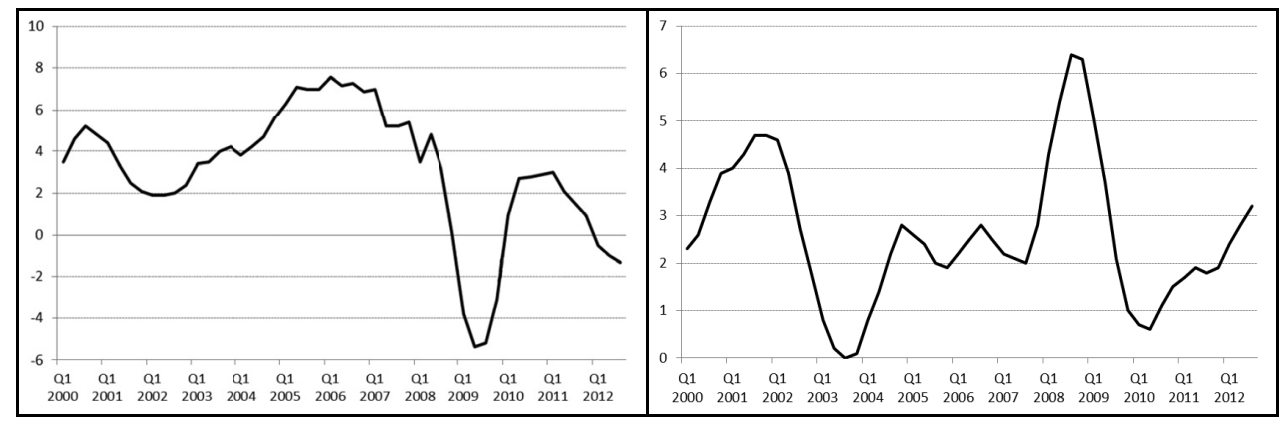


The next important step is the calibration of the structural parameters of our model. The priors of the parameters $\alpha, \beta, \phi_{\pi}, \phi_{y}$ are taken from the HUBERT model, which is used by the Ministry of Finance of the Czech Republic; see Štork et al. (2009). The rest of the structural parameters are taken from previous studies performed on Czech data. If more than one opinion exists, I take an average value. If such a calibration for the Czech economy is not available, calibrations are drawn from Galí, Gertler and López-Salido (2001). Parameter calibration is a lengthy and difficult process and it is not the main topic of this paper. Thus, I take all the prior values from previous studies.

\section{Table 1}

\section{Calibration of all the structural parameters}

\begin{tabular}{|l|l|l|}
\hline Parameter & Prior & Description \\
\hline$\alpha$ & 0.5 & share of capital \\
\hline$\varepsilon$ & 0.99 & discount factor \\
\hline$\theta$ & 1.5 & elasticity of substitution, $m=\log (\varepsilon) /(\varepsilon-1), m=1.1$ \\
\hline$\lambda$ & 0.698 & measure of price stickiness, $0=$ prices are absolutely flexible \\
\hline$\rho$ & 0.154 & $\lambda=\theta^{-1}(1-\theta)(1-\beta \theta)(1-\alpha) /(1-\alpha+\alpha i$ \\
\hline$\sigma$ & $-\log (\beta)$ & real interest rate in the steady state, $\rho=0.0101$ \\
\hline$\phi$ & 1 & coefficient of risk aversion \\
\hline$\phi_{\pi}$ & 0.8 & elasticity of labour supply \\
\hline$\phi_{y}$ & 1.5 & sensitivity of the central bank with respect to inflation \\
\hline$\rho_{a}$ & 0.25 & sensitivity of the central bank with respect to the output gap \\
\hline$\rho_{v}$ & 0.975 & persistence of the technology shock \\
\hline$\eta$ & 0.5 & persistence of the exogenous shock \\
\hline
\end{tabular}

\section{Estimation}

The equilibrium of the NKM is characterised by equations $(1)-(8)$. These equations are rewritten into Dynare which is an open-source add-on to the Matlab or Octave environment. For more details, see Adjemian (2012). Dynare incorporates a comprehensive package of Bayesian techniques, which are used for the estimate. These techniques are described by Koop (2003). The algorithm which is implemented in 
Dynare is described in Schorfheide (2000). A convenient description of the Dynare package is provided by Griffoli (2010) and Villaverde (2009).

The main goal is to find the posterior distribution of all the unknown parameters (conditional on observed data) and it is performed using the Bayesian rule for the conditional probability. The posterior distribution is obtained by a combination of the likelihood function and prior distributions of the estimated parameters. The likelihood function is estimated using the Kalman filter. The posterior distribution is very often an unknown distribution and thus it is necessary to use a numerical technique to generate random samples. Dynare uses the Metropolis-Hastings algorithm for this purpose. This algorithm enables calculation of the basic statistics and moments.

\section{Results of the benchmark model}

The results of the Bayesian estimation are shown in Table 2. It may be observed that the differences between the prior and the posterior values are not significant. It means that the prior values were correctly calibrated. On the other hand, there are very wide confidence intervals. It is caused by the short time series. The log data density is -210.1844 and this statistics is used for comparison of the modified versions of DSGE models. There are only 51 observations for the Czech economy, which is a very limited dataset as compared to, e.g., the US time series data. If the results of the estimation are inserted into equation (4), one can see that the central bank is very sensitive to the level of inflation $\left(\phi_{\pi}\right)$. On the other hand, its sensitivity to the output gap $\left(\phi_{y}\right)$ is not very high. The elasticity of labour supply $(\phi)$ is calibrated to one, and the posterior mean is 0.79 . This means that labour supply is not elastic in the Czech Republic. The share of capital is equal to 0.50 , which means that the share of labour is also 0.50 . This knowledge can be used for any future calibrations of a Cobb-Douglas production function.

\section{Table 2}

Estimation results for the benchmark model

\begin{tabular}{|l|c|c|c|c|c|}
\hline parameter & prior & posterior & lower & upper & distribution \\
\hline$\alpha$ & 0.50 & 0.4978 & 0.4177 & 0.5791 & beta \\
\hline$\phi$ & 0.80 & 0.7928 & 0.7140 & 0.8744 & beta \\
\hline$\phi_{\pi}$ & 1.50 & 1.4946 & 1.4144 & 1.5810 & norm \\
\hline$\phi_{y}$ & 0.25 & 0.2416 & 0.1595 & 0.3206 & norm \\
\hline
\end{tabular}

Figure 3 shows the comparison of the prior distribution and the posterior distribution. 


\section{Figure 3}

\section{The prior and posterior distributions}
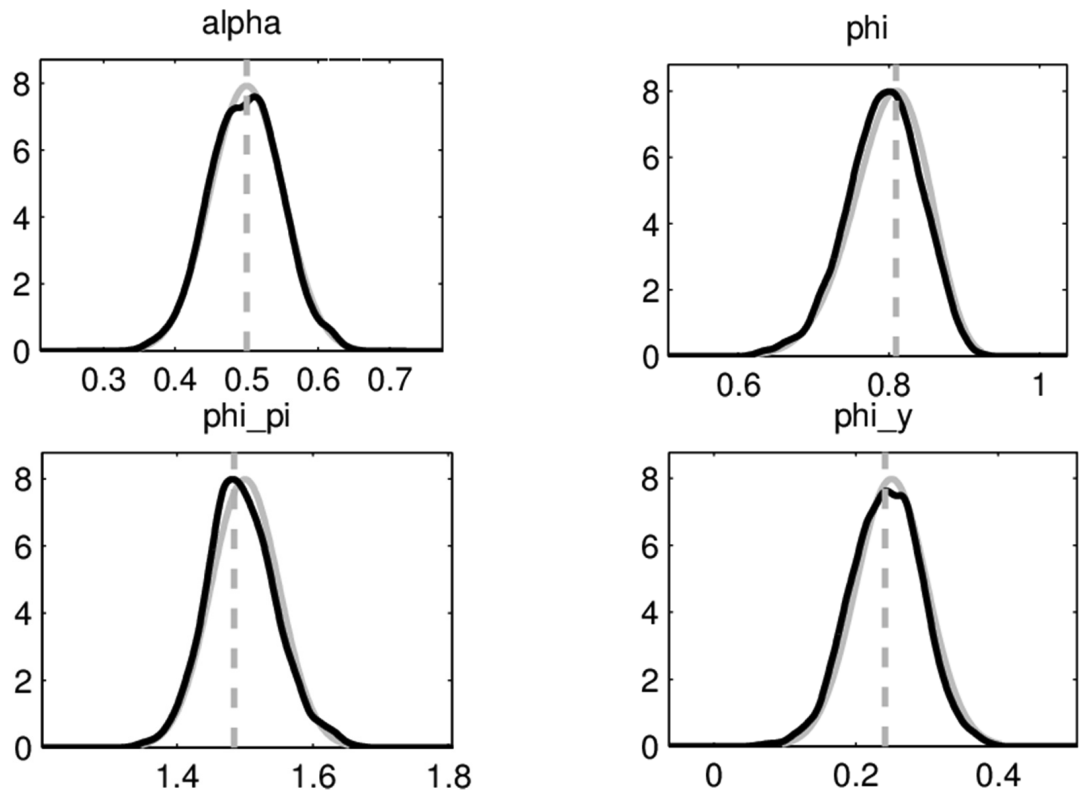

Figure 4 shows the time series of the GDP. The grey columns represent the influence of exogenous shocks and the black columns represent technology shocks. The Czech Republic has experienced both good and bad times and the exogenous shocks have played a crucial role in both of them. During good times, the Czech economy was fuelled by exogenous shocks and very slightly influenced by technology shocks. Bad times are also induced by exogenous shocks and (as opposed to good times) technology shocks have a correcting positive effect.

\section{Figure 4}

\section{GDP and its shock decomposition}
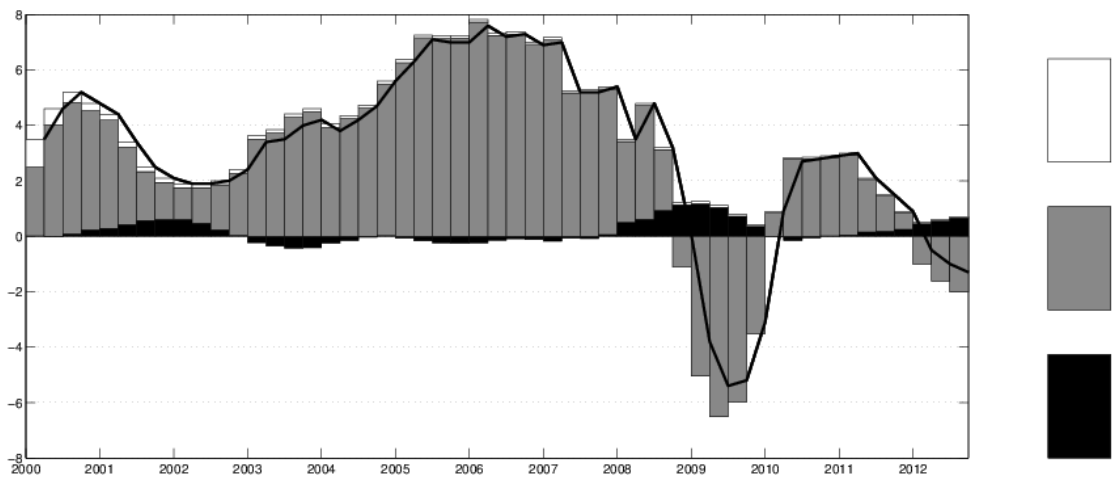
Figure 5 shows the time series of the inflation; the interpretation of the colours is the same as in Figure 4. The initial values play a minor role as they do in Figure 4.

\section{Figure 5}

\section{Inflation and its shock decomposition}

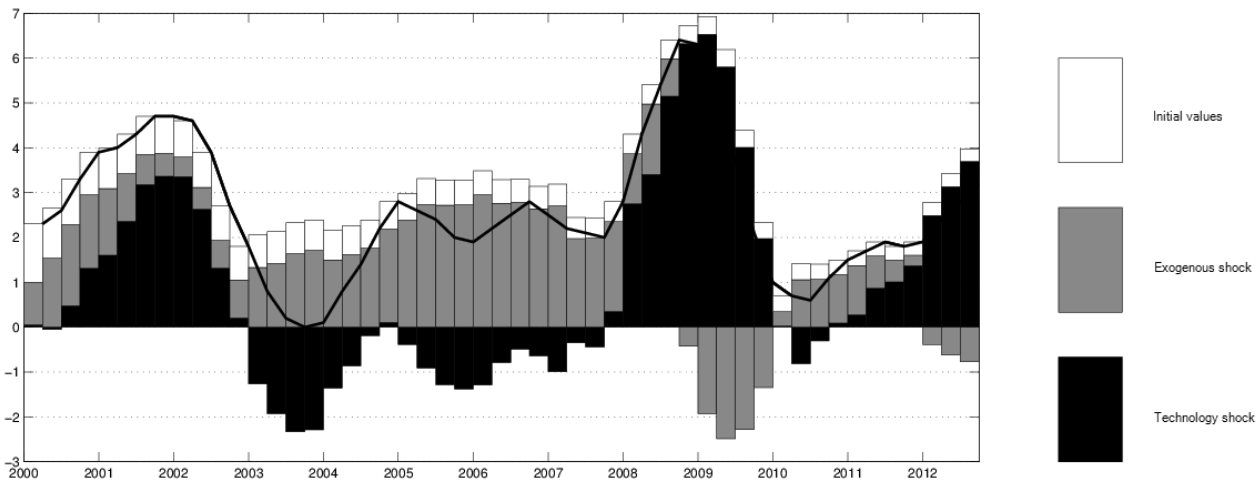

Figure 5 may be interpreted as follows: if the inflation tends to grow very fast, the exogenous shocks mitigate the final effects of the technology shocks. Also, as inflation was very low in 2003-2004, the exogenous shocks caused the inflation to grow. The exogenous shocks had a very positive effect on the Czech economy. The higher level of inflation caused that the GDP growth was not mitigated and lasted for another four years.

\section{The Taylor rule and its modifications}

The benchmark NKM contains an interest rule that is formulated in the spirit of Taylor (1993). This rule is a simple monetary rule that shows how the central bank should adjust its nominal interest rate in a systematic manner in response to the divergences of actual GDP from its potential level and the divergences of actual inflation rates from the inflation target rate. The principal objectives of monetary policy are to dampen business cycle fluctuations, maintain price stability and achieve the maximum sustainable growth. The rule suggested by Taylor (1993) used interest rates as policy instrument to achieve these objectives. The greatest strength and weakness of the Taylor rule is its simplicity. Indeed, its simple structure has pushed many economists to criticise it and led many central bankers to conclude that the coefficients in the rule and the equilibrium interest rate must differ across countries and over time. The first limit concerns the choice of the three variables: inflation, output gap and the neutral (equilibrium) real interest rate. I find different ways of measuring inflation and estimating the equilibrium real interest rate and potential output. The robustness of estimation results can be sensitive to data selection and depend on the estimation of trend GDP, the measure of inflation. The second limit is the timing of the information used by the rule. Taylor used contemporaneous observations of inflation and output in his rule while in reality central banks must rely on lagged information. The structure of the Taylor rule assumes that policy- 
makers consider only current information when making policy decisions and this view is at odds with the forward-looking nature of central banks. Finally, many economists demonstrated that the parameterisation chosen by Taylor reflects exactly the preference of the American monetary authority but they must differ across countries.

It may be observed that there are some limitations; therefore, it is necessary to perform some modifications to the Taylor rule. Subsequently, the NKM is estimated with a modified Taylor rule. The NKM with the modified Taylor rule is formulated in the same way as the benchmark model. Finally, the models are compared using Bayesian techniques, which are described in the next chapter.

The first modification is for the sake of simplification. Here, I suppose that the central bank only takes into account the level of inflation and the output gap is not relevant for the central bank's decision-making process. The simple monetary policy rule can be written as follows

$$
i_{t}=\rho+\phi_{\pi} \pi_{t}+v_{t}
$$

This simple rule is an alternative to the Taylor rule used in the benchmark model.

The second modification is based on Taylor (1993) and discussed by Svensson (1998). According to Srour (2001), there are many reasons for interest rate smoothing. Firstly, the behaviour of the central bank is important for investors and smoothing of interest rates can reduce volatility of a term premium and therefore volatility of long-term interest rates and other financial market instruments. Secondly, the central bank usually has limited information about the shocks hitting the economy. Thirdly, many shocks are serially correlated. The rule takes the following form

$$
i_{t}=\left(1-\phi_{i}\right)\left[\bar{i}+\phi_{\pi} \pi_{t}+\phi_{y} \tilde{y}_{t}\right]+\phi_{i} i_{t-1}+v_{t}
$$

where $\phi_{i}$ is the interest rate smoothing parameter and $\bar{i}$ is the steady-state value of the short-term interest rate.

The third modification is not taken from previous papers. This modification is proposed by the author and its goal is simple. It is desirable to incorporate forward-looking information into the interest rate rule. It may be observed that basic versions of the NKM do not take into account forward-looking information. Two important modifications to the Taylor rule have received wide acceptance. Firstly, Clarida, Galí, and Gertler (1998) departed from the original backward-looking Taylor rule to a forward-looking specification, which arguably better represents the objectives of central banks. In order to control inflation, the policy instrument would respond to the deviation of the inflation forecast from its assumed target. Secondly, Orphanides (2000) stressed the importance of policy rules being operational by showing that there are significant differences between monetary policy evaluated over revised data and over real-time data (i.e., data available to policymakers at the time they are making decisions). Undoubtedly, this is an important topic. This is supported by the fact that the National Bureau of Economic Research has dedicated one chapter in its volume about monetary policy rules to forward-looking rules for monetary policy. For details, see Batini and Haldane (1999). The main goal of the third modification is to specify the forward-looking Taylor rule, 
which is not specified in previous papers. This modification is based on equation (10), which was specified by Svensson. The expected level of inflation and output gap plays a crucial role as well. The interest rule contains expectations of the central bank and is specified as follows

$$
i_{t}=\left(1-\phi_{i}\right)\left\{\bar{i}+E\left[\phi_{\pi} \pi_{t+1}\right]+E\left[\phi_{y} \tilde{y}_{t+1}\right]\right\}+\phi_{i} i_{t-1}+v_{t},
$$

where $E$ is the operator for rational expectations.

To summarise, a DSGE model is a collection of first-order equilibrium conditions that take the general form

$$
\begin{aligned}
E_{t}\left\{f\left(y_{t+1}, y_{t}, y_{t-1}, u_{t}\right)\right\} & =0, \\
E\left(u_{t}\right) & =0,
\end{aligned}
$$

where $y$ represents a vector of endogenous variables of any dimension and $u$ is a vector of exogenous stochastic shocks of any dimension. The solution to this system is a set of equations relating variables in the current period to the past state of the system and current shocks that satisfy the original system. This is what we call the policy function. Sticking to the above notation, we can write this function as

$$
y_{t}=g\left(y_{t-1}, u_{t}\right) \text {. }
$$

Then, it is straightforward to rewrite $y_{t+1}$ as

$$
\begin{aligned}
y_{t+1} & =g\left(y_{t}, u_{t+1}\right), \\
& =g\left(g\left(y_{t-1}, u_{t}\right), u_{t+1}\right) .
\end{aligned}
$$

The complete derivation of this perturbation method is omitted in this paper but available from Griffoli (2010).

\section{Results of the modified models}

This chapter describes results of all the modified NKM. The shock decomposition is not commented on because this type of chart is the same for all the modified NKM. For brevity, only the results of posterior distribution are presented. The model evaluation is performed using marginal likelihood $p\left(Y_{T} \mid M\right)$, which is calculated as follows

$$
p\left(Y_{T} \mid M\right)=\int p\left(Y_{T} \mid \theta, M\right) p(\theta \mid M) d \theta,
$$

where $Y_{T}$ are the observations until the period $T, M$ stands for specific model and $\theta$ represents the parameters of the model $M$. The marginal likelihood $p\left(Y_{T} \mid M\right)$ measures how well the model $M$ predicts the observed data $Y_{T}$. The formal link between the marginal likelihood of a model and its predictive interpretation has been established by Geisel (1975). Integral is unfeasible analytically in most cases. Methods for estimation of the marginal likelihood have been proposed using a sample from posterior distribution. The estimators by Geweke (1999) and Chib and Jeliazkov (2001) are the most popular. 
The posterior results for the simple Taylor rule are as follows.

Table 3

Estimation results for the model with a simple specification of the Taylor rule

\begin{tabular}{|l|c|c|c|c|c|}
\hline parameter & prior & posterior & lower & upper & distribution \\
\hline$\alpha$ & 0.50 & 0.4974 & 0.4147 & 0.5732 & beta \\
\hline$\phi$ & 0.80 & 0.8025 & 0.7253 & 0.8874 & beta \\
\hline$\phi_{\pi}$ & 1.50 & 1.4867 & 1.4005 & 1.5680 & norm \\
\hline
\end{tabular}

The marginal likelihood is -209.4762 , which is lower than the benchmark model in absolute value (-210.1844). It means that the NKM with the simple Taylor rule does not fit the data as well as the benchmark model.

Next, the results of the Svensson specification (10) of the Taylor rule are in the following table.

\section{Table 4}

Estimation results for the model with a Svensson specification of the Taylor rule

\begin{tabular}{|l|c|c|c|c|c|}
\hline parameter & prior & posterior & lower & upper & distribution \\
\hline$\alpha$ & 0.50 & 0.4912 & 0.4089 & 0.5722 & beta \\
\hline$\phi$ & 0.80 & 0.8007 & 0.7183 & 0.8921 & beta \\
\hline$\phi_{\pi}$ & 1.50 & 1.4831 & 1.3992 & 1.5688 & norm \\
\hline$\phi_{y}$ & 0.25 & 0.2665 & 0.1904 & 0.3450 & norm \\
\hline$\phi_{i}$ & 0.70 & 0.5960 & 0.5361 & 0.6517 & norm \\
\hline
\end{tabular}

The marginal likelihood is -209.5511 , which is lower than the benchmark in absolute value (-210.1844) and it means that the Svensson modification does not fit the data as well as the benchmark model.

A forward-looking version (11) of the Taylor rule is specified in this paper. This specification has not been tested in any previous papers about this topic and the results of the posterior distribution are as follows. 


\section{Table 5}

Estimation results for the model with a forward-looking specification of the Taylor rule

\begin{tabular}{|l|c|c|c|c|c|}
\hline parameter & prior & posterior & lower & upper & distribution \\
\hline$\alpha$ & 0.50 & 0.4923 & 0.4135 & 0.5736 & beta \\
\hline$\phi$ & 0.80 & 0.8002 & 0.7124 & 0.8856 & beta \\
\hline$\phi_{\pi}$ & 1.50 & 1.4759 & 1.3934 & 1.5657 & norm \\
\hline$\phi_{y}$ & 0.25 & 0.2651 & 0.1885 & 0.3445 & norm \\
\hline$\phi_{i}$ & 0.70 & 0.5427 & 0.4829 & 0.5997 & norm \\
\hline
\end{tabular}

The marginal likelihood is -214.1717 , which is higher than the benchmark in absolute value (-210.1844). It means that the forward-looking version of the Taylor rule fits the data better than the benchmark model.

It may be observed that the posterior estimates are almost the same for all the modifications of the Taylor rule. However, even if the parameter estimates are almost the same, the fit of the model to the data can be different (especially in the case of the forward-looking modification of the Taylor rule because the estimated parameters have a different economic interpretation than in previous cases). The next chapter is dedicated to a comparison of DSGE models and defines the exact Bayesian statistics which enable us to compare DSGE models.

\section{Bayesian comparison of DSGE models}

A natural method to assess the empirical validity of a DSGE model is to compare its predictive performance, measured by the marginal likelihood, with other available models or perhaps an even larger class of non-structural linear reduced-form models. Having computed the approximation of equation (12), the Bayesian model selection is done by a pairwise comparison of the models through a posterior-odds ratio

$$
P O_{i, j}=\frac{p\left(Y_{T} \mid M_{i}\right) p\left(M_{i}\right)}{p\left(Y_{T} \mid M_{j}\right) p\left(M_{j}\right)}
$$

where $p\left(Y_{T} \mid M_{i}\right)$ is the marginal likelihood of the model $M_{i}, p\left(Y_{T} \mid M_{j}\right)$ is the marginal likelihood of the model $M_{j}, p\left(M_{i}\right)$ is the prior density of the model $M_{i}$, and $p\left(M_{j}\right)$ is the prior density of the model $M_{j}$. The prior odds $\frac{p\left(M_{i}\right)}{p\left(M_{j}\right)}$ are updated by the Bayes factor $B_{i, j}=\frac{p\left(Y_{T} \mid M_{i}\right)}{p\left(Y_{T} \mid M_{j}\right)}$. For more details about DSGE model comparison, see Geweke (1999). Jeffreys (1961) suggested rules of thumb to interpret the Bayes factor as follows. 


\section{Table 6}

\section{Interpretation of the Bayes factor}

\begin{tabular}{|l|l|}
\hline$B_{i j}<1$ & support for $M_{j}$ \\
\hline $1 \leq B_{i j}<3$ & very slight support for $M_{j}$ \\
\hline $3 \leq B_{i j}<10$ & slight evidence against $M_{j}$ \\
\hline $10 \leq B_{i j}<100$ & strong evidence against $M_{j}$ \\
\hline$B_{i j} \geq 100$ & decisive evidence against $M_{j}$ \\
\hline
\end{tabular}

Smets and Wouters (2003) or Adolfson, Laseen, Linde, and Villani (2007) suggest evaluating Bayesian estimated DSGE models based on the point estimates and applying standard statistical tools. This paper includes a benchmark NKM and three modifications of the Taylor rule are specified and estimated in Chapter 5. The Bayesian approach enables us to compare all these models.

\section{Table 7}

The Bayes ratio

\begin{tabular}{|l|c|c|c|c|}
\hline$M_{i} / M_{j}$ & benchmark & simple & svensson & forward \\
\hline benchmark & & 1.936438 & 1.801347 & 0.017558 \\
\hline simple & 0.516412 & & 0.930237 & 0.009067 \\
\hline svensson & 0.55514 & 1.074994 & & 0.009747 \\
\hline forward & 56.954385 & 110.288636 & 102.594607 & \\
\hline
\end{tabular}

The Bayes ratio comparison results may be observed in Table 7. The results are interpreted according to Table 6 . The best modification to the Taylor rule is the forward-looking version. From the forward-looking point of view, there is strong evidence against the NKM with the benchmark Taylor rule and some even more decisive evidence against the NKM with the simple and Svensson Taylor rules. Generally, the results may be interpreted as follows: the forward-looking Taylor rule has the best fit to data. All the other versions of the Taylor rule have almost the same fit to data.

\section{Conclusion}

This paper deals with alternative monetary policy (Taylor) rules. First, the benchmark NKM, which is based on Galí (2008), is specified and estimated using Bayesian techniques. The estimation of the benchmark model is complete. It means that there are figures of prior and posterior distributions and shock decomposition of GDP and inflation. Subsequently, the specification of three alternative monetary policy rules is performed. The charts of prior and posterior distributions and shock decomposition for the alternative monetary policy rules are not presented due to very high coincidence with the benchmark model. Parameter estimates and marginal density are presented for each modification of the monetary policy rule. This paper contains two interesting outputs. 
Firstly, the shock decomposition of GDP comes with the finding that changes to GDP are caused by exogenous shocks. This is valid for both good and bad times. On the other hand, technology shocks play a minor role in GDP formation. The shock decomposition of inflation comes with the following findings. If inflation tends to grow very fast, the exogenous shock mitigates the final effect of the technology shock. On the other hand, the inflation was very low in the Czech Republic in 2003-2004 and started to grow upon an exogenous shock. It had a very positive effect on the Czech economy. The parameter estimates of the NKM with different monetary policy rules are almost the same. However, there are still techniques which can be used for the comparison of DSGE models. Chapter seven introduces these techniques and, using these Bayesian techniques, one is able to compare the predictive power of individual DSGE models. Four NKMs with different monetary policy rules are compared. The benchmark model contains the standard monetary policy rule which is proposed by Galí (2008). Next, the simple, Svensson and forward-looking monetary policy rules are specified and estimated as a part of the NKM.

Secondly, the main result of this paper is that the NKM with the forward-looking monetary policy rule fits data much better than the NKM with the benchmark, simple and Svensson monetary policy rules. This finding confirms that the general opinion on monetary policy rules is valid for the Czech Republic. Relevant foreign studies, e.g., Woodford (2003) or Clarida, Gali, and Gertler (1998), also prove that forward-looking monetary policy rules are much better than their backward-looking counterparts.

\section{References}

ADJEMIAN, S. Dynare: Reference Manual, Version 4 [Dynare Working Papers]. 2012, vol. 1.

ADOLFSON, M.; LASÉEN, S.; LINDÉ, J.; VILLANI, M. Bayesian estimation of an open economy DSGE model with incomplete pass-through. Journal of International Economics. 2007, vol. 72, pp. 481-511.

ARLT, J.; ARLTOVÁ, M. Ekonomické časové řady. Professional Publishing.2009, 290 p. ISBN 978-8086946-856.

BATINI, N.; HALDANE, A. Forward-Looking Rules for Monetary Policy. University of Chicago Press. 1999, 45 p. ISBN 0-226-79124-6.

CALVO, G. Staggered Prices in a Utility-Maximizing Framework. Journal of Monetary Economics. 1983, vol. 12, pp. 383-398.

CHIB, S.; JELIAZKOV, I. Marginal Likelihood From the Metropolis-Hastings Output. Journal of the American Statistical Association. 2001, vol. 96, pp. 270-281.

CLARIDA, R.; GALÍ, J.; GERTLER, M. Monetary Policy Rules and Macroeconomic Stability: Evidence and some Theory [Working Papers 98-01]. 1998, V. Starr Center for Applied Economics, New York University.

GALÍ, J. Monetary policy, inflation, and the business cycle: an introduction to the new Keynesian framework. Princeton University Press. 2008, 203 p. ISBN 06-911-3316-6.

GALÍ, J.; GERTLER, M.; LOPEZ-SALIDO, J. D. European inflation dynamics. European Economic Review. 2001, vol. 45, no. 7, pp. 1237-1270.

GEISEL, M. S. Bayesian comparison of simple macroeconomic models. Studies in Bayesian Econometrics and Statistics: In Honor of Leonard J. Savage. 1975, pp. 227-256.

GEWEKE, J. Using Simulation Methods for Bayesian Econometric Models. Computing in Economics and Finance. 1999, Society for Computational Economics.

GREENE, W. Econometric analysis. 7th ed. Boston: Prentice Hall. 2012, 1198 p. Pearson series in economics. ISBN 978-0-13-139538-1.

GRIFFOLI, T. M. Dynare User Guide [online]. 2010 [cit. 2013-03-24]. www.dynare.org/documentation-and-support/manual. 
JEFFREYS, H. Theory of Probability, 3rd ed. Oxford Classic Texts in the Physical Sciences. 1961, Oxford Univ. Press, Oxford.

KOOP, G. Bayesian econometrics. Hoboken, N.J.: J. Wiley, c2003, xiv, 359 p. ISBN 04-708-4567-8.

KWIATKOWSKI, D.; PHILLIPS, P.; SCHMIDT, P.; SHIN, Y. Testing the Null Hypothesis of Stationarity Against the Alternative of a Unit Root. Journal of Econometrics. 1992, vol. 54, pp. 159-178.

ORPHANIDES, A. Activist stabilization policy and inflation: the Taylor rule in the 1970s. Finance and Economics Discussion Series. 2000, vol. 13, Board of Governors of the Federal Reserve System (U.S.).

ROTEMBERG, J. J. Sticky Prices in the United States. The Journal of Political Economy. 1982, vol. 90, no. 6 , pp. 1187-1211.

SCHORFHEIDE, F. Loss Function Based Evaluation of DSGE Models. Journal of Applied Econometrics. 2000, vol. 15, no. 6, pp. 645-670.

SMETS, F.; WOUTERS, R. An Estimated Dynamic Stochastic General Equilibrium Model of the Euro area. Journal of the European Economic Association. 2003, vol. 1, no. 5, pp. 1123-1175.

SROUR, G. Why Do Central Banks Smooth Interest rates? [Bank of Canada Working Papers]. 2001, vol. 17.

SVENSSON, L. Open -Economy Inflation Targeting. The American Economic Review. 1998, vol. 80.

ŠTORK, Z.; ZÁVACKÁ, J.; VÁVRA, M. HUBERT: a DSGE mode of the Czech economy [Working Paper of Ministry of Finance of the Czech Republic]. 2009, vol. 2, pp. 1-39.

TAYLOR, J. B. Discretion versus policy rules in practice. Journal of business and Economic Statistics.1983, vol. 19.

VILLAVERDE, J. F. The Econometrics of DSGE models [NBER Working Papers 14677].2009, Cambridge.

WOODFORD, M. Interest and prices: foundations of a theory of monetary policy. Woodstock, Oxfordshire [England]: Princeton University Press, c2003, xv, 785 p. ISBN 06-910-1049-8.

\title{
THE NEW KEYNESIAN DSGE MODEL AND ALTERNATIVE MONETARY POLICY RULES IN THE CZECH REPUBLIC
}

\begin{abstract}
The paper deals with a comparison of alternative monetary policy rules also known as Taylor rules. First, a New Keynesian DSGE model is specified. Results of this model are used as a benchmark. These results are obtained using Bayesian techniques. Bayesian techniques are used for both the estimation and the subsequent model comparison. The main experiment introduces three modifications to monetary policy rules. One specifies simple, Svensson and forward-looking monetary policy rules. The estimation is performed on Czech data and the period is from 2000Q1 to 2012Q3. Each specification of the New Keynesian model contains the same observed variables, GDP growth and inflation. The estimation of the benchmark model contains an interesting output as a shock decomposition of both the observed variables. The main finding of this paper is that the parameter estimates of all the modifications of monetary policy rules are almost the same and the log data density looks very similar for all the specified models. On the other hand, a completely opposite conclusion may be derived from the results of the Bayesian comparison of the DSGE models. The key output is that a forward-looking monetary policy rule significantly improves the ability of the New Keynesian DSGE model to fit the observed data.
\end{abstract}

Keywords: New Keynesian model, Dynare, Bayesian estimation, Shock decomposition, DSGE

JEL Classification: O47, E17 